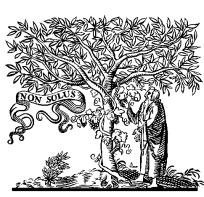

ELSEVIER

\title{
Noninvasive evaluation of ischaemic heart disease: myocardial perfusion imaging or stress echocardiography?
}

\author{
A.F.L. Schinkel ${ }^{a}$, J.J. Bax ${ }^{b}$, M.L. Geleijnse ${ }^{a}$, E. Boersma ${ }^{a}$, A. Elhendy ${ }^{a}$, \\ J.R.T.C. Roelandt ${ }^{a}$, D. Poldermans ${ }^{a^{*}}$ \\ a Thoraxcenter, Department of Cardiology, Erasmus MC, Rotterdam, The Netherlands \\ ${ }^{\mathrm{b}}$ Department of Cardiology, Leiden University Medical Center, Leiden, The Netherlands
}

Received 3 July 2002; revised 27 August 2002; accepted 28 August 2002

\section{Introduction}

Stress echocardiography and myocardial perfusion imaging are commonly used noninvasive imaging modalities for the evaluation of ischaemic heart disease. Both modalities have proved clinically useful in the entire spectrum of coronary artery disease. ${ }^{1-29}$ Both techniques can detect coronary artery disease and provide prognostic information. ${ }^{1-21}$ Both techniques can identify lowrisk and high-risk subsets among patients with known or suspected coronary artery disease and thus guide patient management decisions. ${ }^{18-21}$ In patients with acute myocardial infarction, both techniques have been used to identify residual viable tissue and predict improvement of function over time. ${ }^{22-26}$ In patients with chronic ischaemic left ventricular (LV) dysfunction, viability assessment with either modality can be used to predict improvement of function after revascularisation and thus guide patient treatment. ${ }^{27-29}$

Hence, the use of noninvasive cardiac imaging can help guide management and potentially reduce healthcare costs. ${ }^{30}$ The question remains what is the optimal noninvasive cardiac imaging method in which setting? This article evaluates the value of the two modalities in: (1) the detection of coronary artery disease, (2) the prognosis of coronary artery

\footnotetext{
* Corresponding author. Thoraxcenter Room Ba 300, Department of Cardiology, Erasmus MC, Dr. Molewaterplein 40, 3015 GD Rotterdam, The Netherlands

E-mail address: poldermans@hlkd.azr.nl (D. Poldermans)
}

disease in patients with known or suspected coronary artery disease, (3) prediction of functional recovery following acute myocardial infarction and (4) prediction of functional recovery after revascularisation in patients with chronic ischaemic LV dysfunction. To provide the most objective information, only direct comparative studies on stress echocardiography and perfusion imaging in the same patients are included and pooled analysis of the data was performed.

\section{Methods}

The available studies were identified by MEDLINE searches using the following key words: noninvasive imaging, stress echocardiography, dobutamine, dipyridamole, adenosine, myocardial perfusion imaging, technetium-99m sestamibi, technetium$99 \mathrm{~m}$ tetrofosmin and thallium-201. In addition, a manual search of eight cardiology and nuclear medicine journals (American Heart Journal, American Journal of Cardiology, Circulation, European Heart Journal, Heart, Journal of the American College of Cardiology, Journal of Nuclear Cardiology, Journal of Nuclear Medicine) from January 1975 to 2001 was carried out. Only studies that performed a head-to-head comparison between stress echocardiography and some form of nuclear imaging were selected. From these articles the sensitivity and specificity of the techniques were compared. Studies that did not provide this information were excluded. From the pooled data, 
weighted sensitivities and specificities were calculated. Comparison of sensitivities and specificities was performed using $\mathrm{McNemar}$ testing; a $P$-value $<0.05$ was considered significant.

\section{Results}

\section{Detection of coronary artery disease}

Seventeen direct comparisons (1405 patients) with different stressors (five exercise, two adenosine, one dipyridamole, eight dobutamine, and one combined adenosine and dobutamine) were identified (Table 1). Pooling of the data showed a slightly higher overall sensitivity for myocardial perfusion imaging as compared to stress echocardiography ( 84 vs $80 \%, P<0.05$ ). This finding is in line with the ischaemic cascade (Fig. 1), since perfusion abnormalities (detected by perfusion imaging) proceed systolic dysfunction (detected by stress echocardiography). ${ }^{31}$

On the other hand, stress echocardiography was more specific compared to perfusion imaging ( $86 \mathrm{vs}$ $77 \%, P=0.001$ ). Fig. 2 demonstrates the differences in sensitivity and specificity of the two modalities. It should be noted that the gold standard for the presence/absence of coronary artery disease was angiography in these studies, which may affect specificity of the tests. In the majority of the studies $\geq 50 \%$ stenosis was used as the definition of significant coronary artery disease. In the study of Marwick et al., ${ }^{9}$ results were also analysed with a cutoff of $>70 \%$ stenosis. The results were altered little using this cutoff, as only four patients had a stenosis severity of $50-70 \%$.

Pharmacological stress can be a useful alternative to exercise stress protocols in patients who are unable to exercise because of neurological, orthopedic, or peripheral vascular disease. Because wall motion abnormalities are a consequence of myocardial ischaemia, dobutamine may be more effective than vasodilator (adenosine or dipyridamole) stress echocardiography. ${ }^{32}$ In line with this, combined data from seven direct comparative studies demonstrated that dobutamine stress echocardiography had a higher sensitivity for the diagnosis of coronary artery disease than vasodilator stress echocardiography, while specificity was similar. When dobutamine stress echocardiography was compared to dobutamine or vasodilator perfusion scintigraphy, dobutamine echocardiography was equally sensitive but slightly more specific than perfusion scintigraphy. ${ }^{33}$

Two subgroups of patients were analysed separately: hypertensive patients and female patients.
In patients with hypertension, abnormal thallium perfusion results have been demonstrated in the absence of obstructive coronary artery disease; ${ }^{34,35}$ this may lower specificity. Summarised data from two studies (Table 2, 286 patients) have demonstrated a somewhat higher sensitivity for perfusion imaging compared to stress echocardiography (87 vs $74 \%, P<0.005)$, and confirmed the lower specificity for perfusion imaging ( 44 vs $85 \%, P<0.001$ )..$^{36,37}$

The diagnosis of coronary artery disease in women may be more challenging due to the lower prevalence of coronary artery disease. In addition, single-vessel disease is a common finding in women. ${ }^{38,39}$ The accuracy of perfusion imaging appears to be decreased in women with breast tissue attenuation, ${ }^{39}$ and the smaller LV chamber size in women. ${ }^{40}$ Pooled data from three direct comparisons ${ }^{41-43}$ revealed a comparable sensitivity of the two techniques ( 71 vs $80 \%, P=$ ns) $(175$ patients, Table 2) with a higher specificity of stress echocardiography for the detection of coronary artery disease (72 vs $89 \%, P<0.01$ ). Comparative studies on adenosine stress imaging in patients with hypertension and women are not available. Further research on the relative value of adenosine stress echocardiography and nuclear perfusion imaging in these subgroups is needed.

\section{Prognosis in coronary artery disease}

Noninvasive cardiac imaging is frequently used for risk stratification of patients with known or suspected coronary artery disease. There are two direct comparisons available on the prognostic value of myocardial perfusion imaging and stress echocardiography. Geleijnse et al. ${ }^{18}$ studied 220 patients with chest pain with dobutamine-atropine stress echocardiography and simultaneous technetium-99m sestamibi single photon emission computed tomography (SPECT) imaging. During follow-up of $31 \pm 15$ months, 24 patients had hard cardiac events (nonfatal myocardial infarction or cardiac death). A normal test was related to a good prognosis, with a low annual cardiac event rate of $0.4 \%$ by echocardiography and $0.5 \%$ by perfusion imaging. In that study, stress echocardiography and technetium-99m sestamibi SPECT provided comparable prognostic information.

Olmos et al. ${ }^{19}$ studied 248 patients who underwent exercise echocardiography simultaneously with thallium-201 SPECT. During follow-up (obtained in 225 patients with a mean follow-up of $3.7 \pm 2.0$ years), 64 cardiac events occurred (eight nonfatal infarctions and seven cardiac deaths). A significant difference was observed between 
Table 1 Myocardial perfusion imaging vs stress echocardiography in the diagnosis of coronary artery disease

\begin{tabular}{|c|c|c|c|c|c|c|c|c|c|}
\hline \multirow[t]{2}{*}{ Author } & \multirow[t]{2}{*}{ Year } & \multirow[t]{2}{*}{ Pts } & \multirow{2}{*}{$\begin{array}{l}\text { Definition of } \\
\text { significant } C A D\end{array}$} & \multirow[t]{2}{*}{ Stress } & \multirow[t]{2}{*}{ Tracer } & \multicolumn{2}{|l|}{ Sensitivity } & \multicolumn{2}{|l|}{ Specificity } \\
\hline & & & & & & MPI & Echocardiography & $\mathrm{MPI}$ & Echocardiography \\
\hline Maurer $^{1}$ & 1981 & 36 & $\geq 50 \%$ stenosis & Exercise & Tl-201 & $74 \%(17 / 23)$ & $83 \%(19 / 23)$ & $92 \%(12 / 13)$ & $92 \%(12 / 13)$ \\
\hline Nguyen $^{2}$ & 1990 & 25 & $\geq 50 \%$ stenosis & Adenosine & Tl-201 & $90 \%(18 / 20)$ & $60 \%(12 / 20)$ & $100 \%(5 / 5)$ & $100 \%(5 / 5)$ \\
\hline Galanti $^{3}$ & 1991 & 53 & $\geq 70 \%$ stenosis & Exercise & Tl-201 & $100 \%(27 / 27)$ & $53 \%(25 / 27)$ & $92 \%(24 / 26)$ & $96 \%(25 / 26)$ \\
\hline Pozzoli ${ }^{4}$ & 1991 & 75 & $\geq 50 \%$ stenosis & Exercise & Tc-99m & $84 \%(41 / 49)$ & $71 \%(35 / 49)$ & $88 \%(23 / 26)$ & $96 \%(25 / 26)$ \\
\hline Quinones $^{5}$ & 1992 & 112 & $\geq 50 \%$ stenosis & Exercise & TL-201 & $76 \%(65 / 86)$ & $74 \%(64 / 86)$ & $81 \%(21 / 26)$ & $88 \%(23 / 26)$ \\
\hline Salustri ${ }^{6}$ & 1992 & 44 & $\geq 50 \%$ stenosis & Exercise & Tc-99m & $77 \%(23 / 30)$ & $67 \%(20 / 30)$ & $86 \%(12 / 14)$ & $71 \%(10 / 14)$ \\
\hline Gunalp ${ }^{7}$ & 1993 & 27 & $\geq 50 \%$ stenosis & Dobutamine & Tc-99m & $94 \%(17 / 18)$ & $83 \%(15 / 18)$ & $88 \%(8 / 9)$ & $88 \%(8 / 9)$ \\
\hline Amanullah 8 & 1993 & 40 & $\geq 50 \%$ stenosis & Adenosine & Tc-99m & $94 \%(32 / 34)$ & $74 \%(25 / 34)$ & $100 \%(6 / 6)$ & $100 \%(6 / 6)$ \\
\hline Marwick ${ }^{9}$ & 1993 & 97 & $\geq 50 \%$ stenosis & Adenosine & Tc-99m & $86 \%(51 / 59)$ & $58 \%(34 / 59)$ & $71 \%(27 / 38)$ & $87 \%(33 / 38)$ \\
\hline Marwick ${ }^{9}$ & 1993 & 97 & $\geq 50 \%$ stenosis & Dobutamine & Tc-99m & $80 \%(47 / 59)$ & $85 \%(50 / 59)$ & $74 \%(28 / 38)$ & $82 \%(31 / 38)$ \\
\hline Marwick $^{10}$ & 1993 & 217 & $\geq 50 \%$ stenosis & Dobutamine & Tc-99m & $76 \%(108 / 142)$ & $72 \%(102 / 142)$ & $67 \%(50 / 75)$ & $83 \%(62 / 75)$ \\
\hline Forster ${ }^{11}$ & 1993 & 21 & $\geq 50 \%$ stenosis & Dobutamine & Tc-99m & $83 \%(10 / 12)$ & $75 \%(9 / 12)$ & $89 \%(8 / 9)$ & $89 \%(8 / 9)$ \\
\hline Senior $^{12}$ & 1994 & 61 & $\geq 50 \%$ stenosis & Dobutamine & Tc-99m & $95 \%(42 / 44)$ & $93 \%(41 / 44)$ & $71 \%(12 / 17)$ & $94 \%(16 / 17)$ \\
\hline $\mathrm{Ho}^{13}$ & 1995 & 54 & $\geq 50 \%$ stenosis & Dobutamine & Tl-201 & $98 \%(42 / 43)$ & $93 \%(40 / 43)$ & $73 \%(8 / 11)$ & $73 \%(8 / 11)$ \\
\hline Kisacik $^{14}$ & 1996 & 69 & $\geq 50 \%$ stenosis & Dobutamine & Tc-99m & $96 \%(45 / 47)$ & $94 \%(44 / 47)$ & $64 \%(14 / 22)$ & $86 \%(19 / 22)$ \\
\hline Huang ${ }^{15}$ & 1997 & 93 & $\geq 50 \%$ stenosis & Dobutamine & Tl-201 & $90 \%(60 / 67)$ & $93 \%(62 / 67)$ & $81 \%(21 / 26)$ & $77 \%(20 / 26)$ \\
\hline Parodi ${ }^{16}$ & 1999 & 101 & $\geq 50 \%$ stenosis & Dipyridamole & Tc-99m & $79 \%(63 / 80)$ & $78 \%(62 / 80)$ & $90 \%(19 / 21)$ & $76 \%(16 / 21)$ \\
\hline Smart ${ }^{17}$ & 2000 & 183 & $\geq 50 \%$ stenosis & Dobutamine & Tc- $99 m$ & $80 \%(95 / 119)$ & $87 \%(104 / 119)$ & $73 \%(47 / 64)$ & $91 \%(58 / 64)$ \\
\hline Pooled analysis & & & & & & $84 \%(803 / 959)$ & $80 \%(765 / 959)$ & $77 \%(345 / 446)$ & $86 \%(385 / 446)$ \\
\hline
\end{tabular}

MPI=myocardial perfusion imaging; Tc-99m=Technetium-99m; Tl-201=Thallium-201 chloride. 


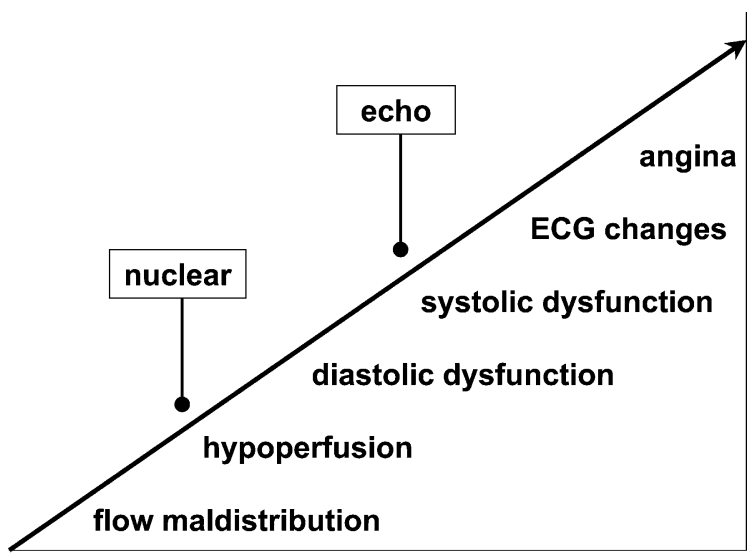

Time from onset of ischemia $\rightarrow$

Fig. 1 The ischaemic cascade represents a sequence of pathophysiologic events caused by coronary artery disease. Nuclear imaging probes an earlier event (hypo-perfusion) in the ischaemic cascade than stress echocardiography does (systolic dysfunction).

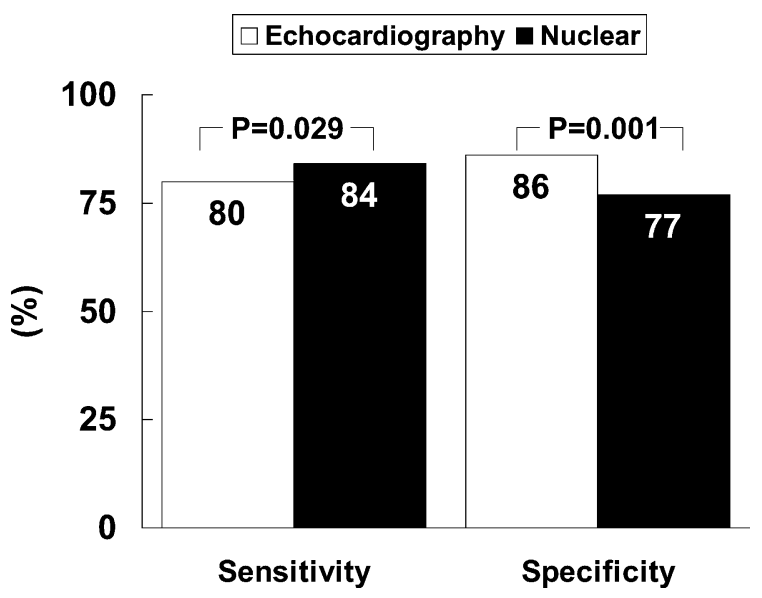

Fig. 2 Sensitivity and specificity of stress echocardiography and nuclear imaging for the detection of coronary artery disease (data based on Refs. 1-17). $\square$ =echocardiography; $\mathbf{\square =}$ nuclear.

patients with normal and abnormal tests for all end points, including death alone, for both modalities. Overall cardiac event rate in patients with normal test results was comparable for both exercise echocardiography and thallium-201 SPECT (1.05 vs $1.13 \%$, ns). Annual cardiac death rate was favorably low for both normal echocardiography and normal SPECT imaging (0.08 vs $0.08 \%$, ns). Since only two direct comparisons are available, more large studies are required to fully elucidate the relative prognostic value of myocardial perfusion imaging and stress echocardiography.

\section{Assessment of myocardial viability}

The hallmark of viability on dobutamine echocardiography is the improvement of wall motion during the infusion of low-dose dobutamine $\left(5-10 \mu \mathrm{kg}^{-1} \mathrm{~min}^{-1}\right)$. More recent studies have employed a low-high dose protocol (with dosages up to $40 \mu \mathrm{g} \mathrm{kg}^{-1} \mathrm{~min}^{-1}$, with the addition of atropine). This protocol allows assessment of both viability (response during low-dose dobutamine) and stress-induced ischaemia (response during high-dose dobutamine). For nuclear imaging, different techniques are available. Thallium-201 imaging can be used to evaluate perfusion and cell membrane integrity. Two protocols are used mainly: rest-redistribution imaging and stressredistribution-reinjection imaging. ${ }^{27-29}$ While restredistribution imaging provides only information on myocardial viability, the reinjection protocol allows assessment of stress-induced ischaemia and viability.

Technetium-99m sestamibi can be used to assess perfusion and intact mitochondria. Sestamibi imaging is performed under resting conditions; in the absence of a stress study, this protocol only provides information on viability. It has been demonstrated that the addition of nitrates before tracer administration enhances viability detection. ${ }^{44}$

Glucose utilisation can be evaluated with F18-fluorodeoxyglucose (FDG). FDG imaging can nowadays be performed with positron emission tomography and SPECT. The introduction of SPECT imaging has contributed to a more widespread use of FDG. ${ }^{45}$ Generally, cardiac FDG uptake is compared with regional perfusion. Viability is defined when perfusion/FDG uptake is normal, or when perfusion is reduced with enhanced FDG uptake.

\section{Prediction of functional recovery after acute myocardial infarction}

The phenomenon of reversible dysfunction after myocardial infarction, known as stunning has been well established. ${ }^{46,47}$ The presence of viable, but stunned myocardium has been used to predict functional recovery. Five studies ${ }^{22-26}$ with 209 patients and 958 dyssynergic myocardial segments, compared perfusion imaging with stress echocardiography in the same patient population after acute myocardial infarction and aimed at the prediction of recovery of function (Table 3 ). All of these studies used dobutamine stress, in most studies a low-dose dobutamine protocol was employed for echocardiography. Nuclear imaging tended to have a higher sensitivity (although not significant), 
Table 2 Myocardial perfusion imaging vs stress echocardiography in special patient subsets

\begin{tabular}{|c|c|c|c|c|c|c|c|c|c|}
\hline \multirow[t]{2}{*}{ Author } & \multirow[t]{2}{*}{ Year } & \multirow[t]{2}{*}{ Pts } & \multirow{2}{*}{$\begin{array}{l}\text { Definition } \\
\text { of significant } \\
\text { CAD }\end{array}$} & \multirow[t]{2}{*}{ Stress } & \multirow[t]{2}{*}{ Tracer } & \multicolumn{2}{|l|}{ Sensitivity } & \multicolumn{2}{|l|}{ Specificity } \\
\hline & & & & & & MPI & $\begin{array}{l}\text { Echo- } \\
\text { cardiography }\end{array}$ & MPI & $\begin{array}{l}\text { Echo- } \\
\text { cardiography }\end{array}$ \\
\hline \multicolumn{10}{|c|}{ Hypertension } \\
\hline Elhendy ${ }^{36}$ & 1998 & 84 & $\geq 50 \%$ stenosis & Dobutamine & Tc-99m & $67 \%(44 / 66)$ & $73 \%(48 / 66)$ & $83 \%(15 / 18)$ & $83 \%(15 / 18)$ \\
\hline Fragasso $^{37}$ & 1999 & 101 & $\geq 50 \%$ stenosis & Dipyridamole & Tc- $99 m$ & $98 \%(56 / 57)$ & $61 \%(35 / 57)$ & $36 \%(16 / 44)$ & $91 \%(40 / 44)$ \\
\hline Fragasso $^{37}$ & 1999 & 101 & $\geq 50 \%$ stenosis & Dobutamine & Tc-99m & $98 \%(56 / 57)$ & $88 \%(50 / 57)$ & $36 \%(16 / 44)$ & $80 \%(35 / 44)$ \\
\hline $\begin{array}{l}\text { Pooled } \\
\text { analysis } \\
\text { Women }\end{array}$ & & & & & & $87 \%(156 / 180)$ & $74 \%(133 / 180)$ & $44 \%(47 / 106)$ & $85 \%(90 / 106)$ \\
\hline Takeuchi $^{41}$ & 1996 & 61 & $\geq 50 \%$ stenosis & Dobutamine & Tl-201 & $78 \%(14 / 18)$ & $72 \%(13 / 18)$ & $70 \%(30 / 43)$ & $91 \%(39 / 43)$ \\
\hline Elhendy ${ }^{42}$ & 1998 & 70 & $\geq 50 \%$ stenosis & Dobutamine & Tc-99m & $64 \%(29 / 45)$ & $78 \%(35 / 45)$ & $72 \%(18 / 25)$ & $92 \%(23 / 25)$ \\
\hline $\mathrm{Ho}^{43}$ & 1998 & 44 & $\geq 50 \%$ stenosis & Dobutamine & Tl-201 & $79 \%(19 / 24)$ & $92 \%(22 / 24)$ & $75 \%(15 / 20)$ & $80 \%(16 / 20)$ \\
\hline $\begin{array}{l}\text { Pooled } \\
\text { analysis }\end{array}$ & & & & & & $71 \%(62 / 87)$ & $80 \%(70 / 87)$ & $72 \%(63 / 88)$ & $89 \%(78 / 88)$ \\
\hline
\end{tabular}

MPI=myocardial perfusion imaging; Tc-99m=Technetium-99m; TL-201=Thallium-201 chloride.

Table 3 Prediction of recovery of function after acute myocardial infarction: myocardial perfusion imaging vs stress echocardiography

\begin{tabular}{|c|c|c|c|c|c|c|c|c|}
\hline \multirow[t]{2}{*}{ Author } & \multirow[t]{2}{*}{ Year } & \multirow[t]{2}{*}{ Pts } & \multirow{2}{*}{$\begin{array}{l}\text { Dyssynergic } \\
\text { segments }\end{array}$} & \multirow[t]{2}{*}{ Techniques } & \multicolumn{2}{|l|}{ Sensitivity } & \multicolumn{2}{|l|}{ Specificity } \\
\hline & & & & & MPI & Echocardiography & MPI & Echocardiography \\
\hline Elhendy ${ }^{22}$ & 1996 & 32 & 112 & $\begin{array}{l}\text { TL-201 RR vs } \\
\text { LDDE }\end{array}$ & $77 \%(27 / 35)$ & $77 \%(27 / 35)$ & $57 \%(44 / 77)$ & $84 \%(65 / 77)$ \\
\hline Le Feuvre ${ }^{23}$ & 1996 & 45 & 235 & $\begin{array}{l}\text { TL-201 RI vs } \\
\text { LDDE }\end{array}$ & $54 \%(59 / 109)$ & $53 \%(58 / 109)$ & $88 \%(111 / 126)$ & $95 \%(120 / 126)$ \\
\hline Smart $^{24}$ & 1997 & 64 & 399 & $\begin{array}{l}\text { Tl-201 RR vs } \\
\text { HDDE }\end{array}$ & $68 \%(140 / 207)$ & $88 \%(183 / 207)$ & $70 \%(134 / 192)$ & $80 \%(153 / 192)$ \\
\hline Spinelli ${ }^{25}$ & 1999 & 49 & 108 & $\begin{array}{l}\text { Tl-201 vs } \\
\text { LDDE }\end{array}$ & $87 \%(53 / 61)$ & $66 \%(40 / 61)$ & $74 \%(35 / 47)$ & $89 \%(42 / 47)$ \\
\hline Anselmi $^{26}$ & 2000 & 19 & 104 & $\begin{array}{l}\text { Tl-201 RR vs } \\
\text { LDDE }\end{array}$ & $88 \%(23 / 26)$ & $69 \%(18 / 26)$ & $36 \%(28 / 78)$ & $88 \%(69 / 78)$ \\
\hline Pooled analysis & & & & & $69 \%(302 / 438)$ & $74 \%(326 / 438)$ & $68 \%(352 / 520)$ & $86 \%(449 / 520)$ \\
\hline
\end{tabular}

HDDE=low-high dose dobutamine echocardiography; LDDE=low-dose dobutamine echocardiography; MPI=myocardial perfusion imaging; RI=reinjection; RR=rest-redistribution; Tl-201=thallium-201 chloride.

whereas stress echocardiography was more specific in the prediction of recovery of function (Fig. 3).

\section{Prediction of functional recovery after revascularisation in chronic ischaemic LV dysfunction}

Table 4 shows the accuracy of different viability techniques for the prediction of improvement of function after revascularisation. ${ }^{29}$ The nuclear imaging techniques appear to have a higher sensitivity for the prediction of functional recovery whereas stress echocardiography appears more specific. Various studies have directly compared some form of nuclear imaging to stress echocardiography. Panza et al. ${ }^{48}$ have performed a head-to-head comparison between thallium-201 imaging and dobutamine stress echocardiography in patients with chronic ischaemic LV dysfunction. A total of 311 segments were analysed by both techniques; $84 \%$ of these were classified as viable and $16 \%$ as nonviable on thallium-201 imaging. The majority of the 'thallium-201 nonviable segments' did not exhibit contractile reserve. However, an additional $36 \%$ of the 'thallium-201 viable segments' also did not exhibit contractile reserve. Thus, the results indicated that thallium-201 imaging was more sensitive than dobutamine echocardiography for the detection of viable tissue. Similar results were obtained by Cornel et al. ${ }^{49}$ who evaluated 40 patients with chronic ischaemic LV dysfunction with FDG imaging and dobutamine echocardiography. Again, nuclear imaging was more sensitive for the detection of viable tissue as 


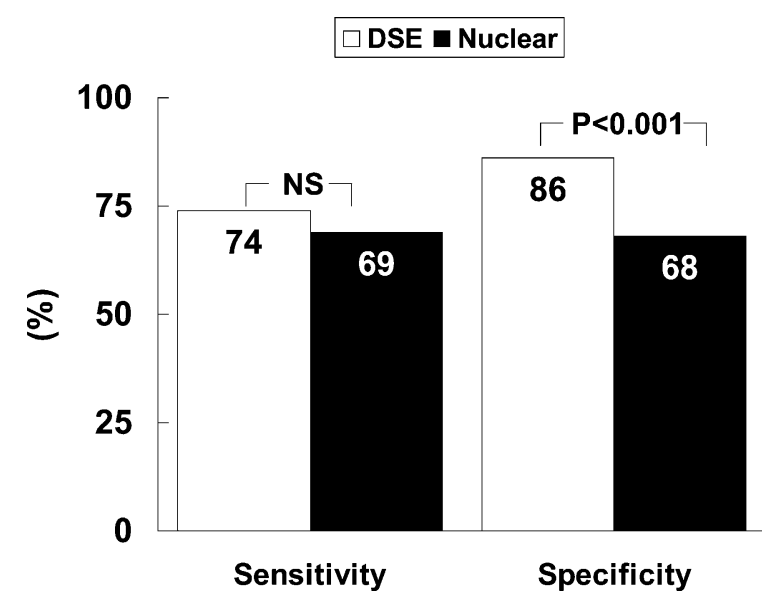

Fig. 3 Sensitivity and specificity of dobutamine stress echocardiography and nuclear imaging for the prediction of functional outcome in acute myocardial infarction (data based on Refs. 22-26). $\square=$ DSE; $\square=$ nuclear.

evidenced by the $27 \%$ of the dysfunctional segments with FDG uptake but without contractile reserve (Fig. 4).

Various studies have subsequently compared the predictive accuracy of nuclear imaging with dobutamine echocardiography. Currently, a total of 18 studies $^{50-67}$ (with 563 patients) have performed a direct comparison between the two modalities (Table 5). Different nuclear techniques were used: three studies used FDG PET, five thallium-201 reinjection and 10 thallium-201 rest-redistribution. Two studies used low-high dose dobutamine echocardiography and the remaining 16 used lowdose dobutamine echocardiography. Pooling of these data yielded a higher sensitivity for nuclear imaging $(88$ vs $76 \%, P<0.05)$ and a higher specificity for dobutamine echocardiography (81 vs $53 \%$, $P<0.05$ ). In eight studies (see Table 5 ), some form of stress imaging (either thallium-201 reinjection or low-high dose dobutamine echocardiography) was used; to make the comparison more balanced (and only restricted to viability assessment) the analysis was repeated after exclusion of these eight studies. The discrepancy between nuclear imaging and dobutamine echocardiography for the prediction of functional outcome after revascularisation became even more outspoken (Fig. 5).

It is conceivable that different levels of ultrastructural cell damage account for this discrepancy: the inotropic response during dobutamine stimulation may be lost while more basal characteristics such as cell membrane integrity and glucose utilisation are still intact. Besides prediction of improvement of function after revascularisation, prediction of long-term survival may be more important. Currently, no direct comparative studies are available on the prognostic value of nuclear imaging and stress echocardiography in patients with ischaemic cardiomyopathy.

\section{Recent developments: simultaneous assessment of function and perfusion}

Recently, different technical developments have been implemented in both perfusion imaging and stress echocardiography that further optimised the techniques. Myocardial perfusion imaging has been improved by the introduction of new cameras, imaging protocols, attenuation and scatter correction. ${ }^{68,69}$ For echocardiography, second harmonic imaging has markedly improved endocardial border detection, which could even be further enhanced by intravenous administration of contrast agents that opacify the LV cavity. ${ }^{70-72}$ Colour kinesis and tissue Doppler echocardiography may allow quantification of function, ${ }^{73,74}$ which may enhance reproducibility and diagnostic accuracy.

Other recent developments have aimed at providing integrated information on function and perfusion. Both gated SPECT imaging and contrast echocardiography allow simultaneous assessment of function and perfusion. ${ }^{75,76}$ Over the past 5 years ECG-gated SPECT has become state-of-the-art in cardiac myocardial perfusion imaging. Various comparative studies have demonstrated excellent accuracy of gated SPECT for the assessment of both regional and global LV function. ${ }^{77}$ Smanio et al. ${ }^{78}$ have demonstrated that combination of perfusion and function (assessed by gating) resulted in significantly higher diagnostic accuracy for detection/ exclusion of coronary artery disease. Moreover, the integrated information of function and perfusion allows superior prognostification in patients with known or suspected coronary artery disease, as demonstrated recently by Sharir et al. ${ }^{79}$

Contrast echocardiography also allows simultaneous assessment of function and perfusion. With the introduction of contrast agents that can be administered intravenously, the use of contrast echocardiography has now become feasible outside the catheterisation laboratory. In combination with harmonic and intermittent imaging, quantitative assessment of perfusion has become possible.

Recently, Kaul et al. ${ }^{80}$ have shown an excellent concordance between contrast echocardiography and myocardial perfusion imaging. In 30 patients, the agreement for detecting absence/presence of coronary artery disease was $86 \%$. However, two multicentre trials have demonstrated a less favourable agreement between perfusion imaging and 
Table 4 Accuracy of the different viability techniques (data based on pooled analysis of data available in the literature ${ }^{29}$ )

\begin{tabular}{lllllll}
\hline Technique & No. of studies & No. of pts & Sensitivity (\%) & Specificity (\%) & PPV (\%) & NPV (\%) \\
\hline DSE & 32 & 1090 & 81 & 80 & 77 & 85 \\
Tl-201 RR & 22 & 557 & 86 & 59 & 69 & 80 \\
Tl-201 RI & 11 & 301 & 88 & 50 & 57 & 83 \\
MIBI & 20 & 488 & 81 & 66 & 71 & 77 \\
FDG PET & 20 & 598 & 93 & 58 & 71 & 86 \\
\hline
\end{tabular}

DSE=dobutamine stress echocardiography; FDG=F18-fluorodeoxyglucose; MIBI=technetium-99m sestamibi; NPV=negative predictive value; $\mathrm{PET}=$ positron emission tomography; $\mathrm{PPV}=$ positive predictive value; $\mathrm{RR}=$ rest-redistribution; $\mathrm{RI}=$ reinjection; Tl-201=thallium-201 chloride.

\section{FDG nonviable}

\author{
$96 \%$ \\ contractile reserve -
}

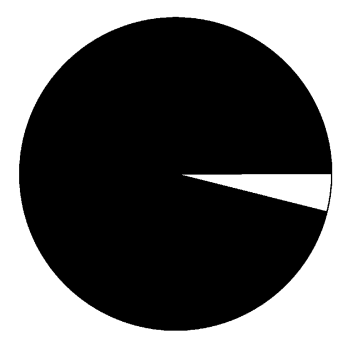

4\%
contractile reserve +

\section{FDG viable}

\author{
$20 \%$ \\ contractile reserve -
}

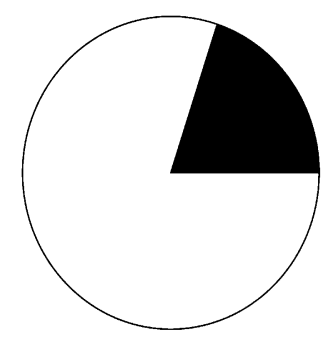

\section{$80 \%$ contractile reserve +}

Fig. 4 Agreement and disagreement between FDG SPECT and low-dose dobutamine echocardiography in dysfunctional myocardium (reprinted with permission from Cornel et al. ${ }^{49}$ ).

contrast echocardiography. ${ }^{81,82}$ Marwick et al. ${ }^{81}$ showed that, for the detection of extensive perfusion defects on SPECT perfusion imaging, contrast echocardiography had a sensitivity ranging from 13 to $48 \%$ with a specificity ranging from 63 to $100 \%$. Jucquois et al. ${ }^{82}$ suggested that the discrepancy between the two techniques could in part be related to attenuation artifacts on SPECT (inferior wall) and suboptimal visualisation of the anterior and lateral walls by echocardiography. However, in experienced settings, adequate quantification of myocardial blood flow and quantification of coronary artery stenoses is possible, as demonstrated by Wei and colleagues. ${ }^{83,84}$ Besides detection of coronary artery disease, evaluation of patients with acute myocardial infarction is feasible with contrast echocardiography and is particularly useful for assessment of 'the no-reflow phenomenon' after thrombolysis or percutaneous interventions. ${ }^{85,86}$ Finally, the feasibility of contrast echocardiography for assessment of viability after acute infarction $^{87}$ and in the setting of chronic LV dysfunction ${ }^{88}$ has been demonstrated.

Thus, in the near future, the combined assessment of perfusion and function by echocardiography and SPECT will allow a more complete assessment of patients with coronary artery disease.

\section{Clinical implications and conclusions}

Both myocardial perfusion imaging and stress echocardiography have proved to be extremely useful noninvasive tests for the evaluation of coronary artery disease. ${ }^{1-29}$ Due to basic differences between the two tests, perfusion imaging is a sensitive test with a somewhat lower specificity 
Table 5 Head-to-head comparisons between nuclear imaging and dobutamine echocardiography for the prediction of improvement of regional function post-revascularisation (table modified from Ref. 29)

\begin{tabular}{|c|c|c|c|}
\hline Author & Techniques & Assessing & No. of pts \\
\hline Gerber $^{50}$ & FDG PET vs LDDE & V vs V & 39 \\
\hline Baer $^{51}$ & FDG PET vs LDDE & V vs V & 42 \\
\hline Pagano $^{52}$ & FDG PET vs LDDE & V vs V & 30 \\
\hline Vanoverschelde $\mathrm{e}^{53}$ & TI-201 RI vs LDDE & $V+I$ vs V & 73 \\
\hline Arnese $^{54}$ & TI-201 RI vs LDDE & V+l vs V & 38 \\
\hline$B a x^{55}$ & TI-201 RI vs LDDE & $\mathrm{V}+\mathrm{l}$ vs V & 17 \\
\hline Haque $^{56}$ & TL-201 RI vs LDDE & $V+I$ vs $V$ & 26 \\
\hline Kostopoulos ${ }^{57}$ & TI-201 RI vs LDDE & V+l vs V & 31 \\
\hline Marzullo 58 & Tl-201 RR vs LDDE & V vs V & 14 \\
\hline Qureshi ${ }^{59}$ & TL-201 RR vs HDDE & V vs $V+1$ & 34 \\
\hline Alfieri ${ }^{60}$ & TL-201 RR vs LDDE & V vs V & 13 \\
\hline Perrone-Filardi ${ }^{61}$ & TL-201 RR vs LDDE & VvsV & 18 \\
\hline Charney $^{62}$ & TL-201 RR vs LDDE & V vs V & 14 \\
\hline Nagueh $^{63}$ & Tl-201 RR vs HDDE & V vs V+I & 19 \\
\hline Pace $^{64}$ & Tl-201 RR vs LDDE & V vs V & 46 \\
\hline Senior ${ }^{65}$ & TI-201 RR vs LDDE & V vs V & 22 \\
\hline Sicari ${ }^{66}$ & Tl-201 RR vs LDDE & V vs V & 57 \\
\hline Gunning ${ }^{67}$ & Tl-201 RR vs LDDE & V vs V & 30 \\
\hline
\end{tabular}

FDG=F 18-fluorodeoxyglucose; HDDE=low-high dose dobutamine echocardiography; I=stress-inducible ischaemia; LDDE= low-dose dobutamine echocardiography; PET=positron emission tomography; RI=reinjection; RR=rest-redistribution; Tl-201= thallium-201 chloride; V=viability.

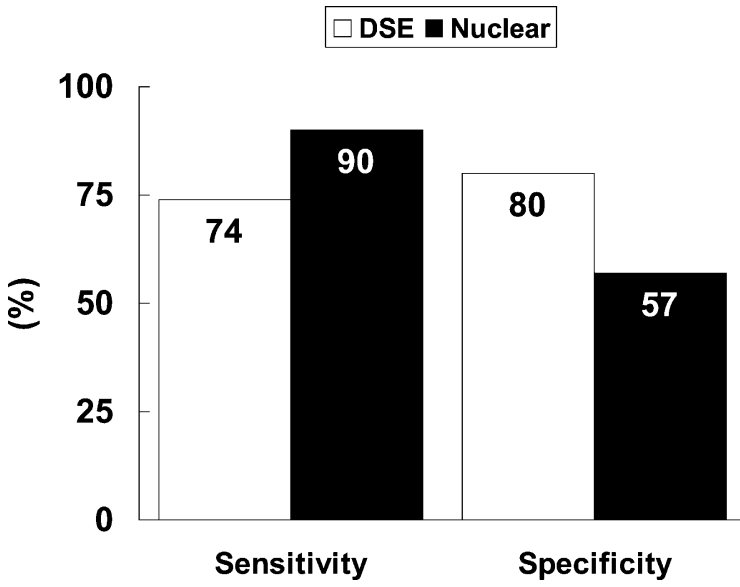

Fig. 5 Bar graph illustrating sensitivities and specificities of nuclear imaging and dobutamine stress echocardiography to predict improvement of function post-revascularisation in patients with chronic ischaemic left ventricular dysfunction (data based on Refs. 50-52,58,60-62). $\square=$ DSE; $\square=$ nuclear.

for the detection of coronary artery disease; the converse is true for stress echocardiography. ${ }^{1-17}$ This systematic review focuses on direct comparative studies on stress echocardiography and perfusion imaging in order to provide the most objective information. Nevertheless, a potential risk of pooling data from different studies is to mix patients with different clinical characteristics and risk profile.

Two available direct head-to-head comparative studies demonstrated a similar prognostic value of perfusion imaging and stress echocardiography. Larger comparisons are needed to draw further conclusions.

For the assessment of myocardial viability after acute infarction the modalities seem to be equally sensitive, whereas stress echocardiography is the more specific test. ${ }^{22-26}$ Hence, for the early assessment of viability stress echocardiography may be preferable. However, specificity is determined by segments that are nonviable that do not improve in function. A lower specificity suggests that a substantial percentage of segments that are viable do not recover in function. Most studies have evaluated recovery of function at a rather short time-interval after infarction ( $<3$ months) and longer follow-up may be needed.

In patients with chronic ischaemic ventricular dysfunction, nuclear imaging has a high sensitivity for the detection of viable myocardium and a low specificity, whereas the converse is true for stress echocardiography. ${ }^{50-67}$ The lower specificity of nuclear imaging can again be an issue of duration of follow-up. Recent data have demonstrated that a substantial percentage of segments need longer time after revascularisation to (fully) recover in function. ${ }^{89}$ In addition, large direct comparative studies are required to evaluate the prognostic value of nuclear imaging and stress echocardiography in patients with chronic ischaemic left ventricular dysfunction. 
In conclusion, the current analysis demonstrated that both techniques are useful in the evaluation of patients with coronary artery disease, although small differences between accuracies exist in different settings. The most important factor for using a test remains the local expertise and availability of these imaging modalities. In addition, patient characteristics (habitus, acoustic window, pregnancy) may influence the choice of the technique, and finally the studies discussed generally reflect the experience in university centers and many of these studies may be influenced by selection and referral bias, which limits application of the results to the general population.

\section{References}

1. Maurer G, Nanda NC. Two-dimensional echocardiographic evaluation of exercise induced left and right ventricular asynergy: correlation with thallium scanning. Am J Cardiol 1981;48:720-7.

2. Nguyen T, Heo J, Ogilby JD et al. Single photon emission computed tomography with thallium-201 during adenosineinduced coronary hyperemia: correlation with coronary arteriography, exercise thallium imaging and twodimensional echocardiography. J Am Coll Cardiol 1990; 16:1375-83.

3. Galanti G, Sciagra R, Comeglio M et al. Diagnostic accuracy of peak exercise echocardiography in coronary artery disease: comparison with thallium-201 myocardial scintigraphy. Am Heart J 1991;122:1609-16.

4. Pozzoli MMA, Fioretti PM, Salustri A et al. Exercise echocardiography and technetium $99 \mathrm{~m} \mathrm{MIBI}$ single photon emission computed tomography in the detection of coronary artery disease. Am J Cardiol 1991;67:350-5.

5. Quiñones MA, Verani MS, Haichin RM et al. Exercise echocardiography versus thallium-201 single-photon emission computed tomography in evaluation of coronary artery disease. Circulation 1992;85:1026-31.

6. Salustri A, Pozzoli MMA, Hermans W et al. Relationship between exercise echocardiography and perfusion singlephoton emission computed tomography in patients with single-vessel coronary artery disease. Am Heart J 1992; 124:75-83.

7. Günalp B, Dokumaci B, Uyan C et al. Value of dobutamine technetium-99m-sestamibi SPECT and echocardiography in the detection of coronary artery disease compared with coronary angiography. J Nucl Med 1993;34:889-94.

8. Amanullah AM, Bevegard S, Lindvall $\mathrm{K}$ et al. Assessment of left ventricular wall motion in angina pectoris by twodimensional echocardiography and myocardial perfusion by technetium-99m sestamibi tomography during adenosineinduced coronary vasodilatation and comparison with coronary angiography. Am J Cardiol 1993;72:983-9.

9. Marwick T, Willemart B, D'Hondt AM et al. Selection of the optimal nonexercise stress for the evaluation of ischemic regional myocardial dysfunction and malperfusion. Comparison of dobutamine and adenosine using echocardiography and $99 \mathrm{mTC}-\mathrm{MIBI}$ single photon emission computed tomography. Circulation 1993;87:345-54.

10. Marwick T, D'Hondt AM, Baudhin T et al. Optimal use of dobutamine stress for the detection and evaluation of cor- onary artery disease: combination with echocardiography or scintigraphy, or both? J Am Coll Cardiol 1993;22:159-67.

11. Forster T, MCNeill AJ, Salustri A et al. Simultaneous dobutamine stress echocardiography and technetium-99m isonitrile single-photon emission computed tomography in patients with suspected coronary artery disease. J Am Coll Cardiol 1993;21:1591-6.

12. Senior R, Sridhara BS, Anagnostou E et al. Synergistic value of simultaneous stress dobutamine sestamibi single-photon emission computerized tomography and echocardiography in the detection of coronary artery disease. Am Heart $J$ 1994;128:713-8.

13. Ho FM, Huang PJ, Liau CS et al. Dobutamine stress echocardiography compared with dipyridamole thallium-201 single-photon emission computed tomography in detecting coronary artery disease. Eur Heart J 1995;16:570-5.

14. Kisacik HL, Özdemir K, Altinyay E et al. Comparison of exercise testing with simultaneous dobutamine stress echocardiography and technetium-99m isotrinile singlephoton emission computerized tomography for diagnosis of coronary artery disease. Eur Heart J 1996;17:113-9.

15. Huang PJ, Ho YL, Wu CC et al. Simultaneous dobutamine stress echocardiography and thallium-201 perfusion imaging for the detection of coronary artery disease. Cardiology 1997;88:556-62.

16. Parodi G, Picano E, Marcassa $C$ et al. High dose dipyridamole myocardial imaging: simultaneous sestamibi scintigraphy and two-dimensional echocardiography in the detection and evaluation of coronary artery disease. Italian Group of Nuclear Cardiology. Coron Artery Dis 1999;10:177-84.

17. Smart SC, Bhatia A, Hellman R et al. Dobutamine-atropine stress echocardiography and dipyridamole sestamibi scintigraphy for the detection of coronary artery disease: limitations and concordance. J Am Coll Cardiol 2000; 36:1265-73.

18. Geleijnse ML, Elhendy A, Van Domburg RT et al. Cardiac imaging for risk stratification with dobutamine atropine stress testing in patients with chest pain. Circulation 1997; 96:137-47.

19. Olmos LI, Dakik H, Gordon R et al. Long-term prognostic value of exercise echocardiography compared with exercise 201Tl, ECG, and clinical variables in patients evaluated for coronary artery disease. Circulation 1998;98:2679-86.

20. Brown KA. Do stress echocardiography and myocardial perfusion imaging have the same ability to identify the low-risk patient with known or suspected coronary artery disease? Am J Cardiol 1998;81:1050-3.

21. Brown KA. Prognostic value of thallium-201 myocardial perfusion imaging: a diagnostic tool comes of age. Circulation 1991;83:363-81.

22. Elhendy A, Trocino G, Salustri A et al. Low-dose dobutamine echocardiography and rest-redistribution thallium-201 tomography in the assessment of spontaneous recovery of left ventricular function after recent myocardial infarction. Am Heart J 1996;131:1088-96.

23. Le Feuvre $\mathrm{C}$, Baubion N, Aubry $\mathrm{N}$ et al. Assessment of reversible dyssynergic segments after acute myocardial infarction: dobutamine echocardiography versus thallium201 single photon emission computed tomography. Am Heart J 1996;131:668-75.

24. Smart SC, Stoiber T, Hellman R et al. Low dose dobutamine echocardiography is more predictive of reversible dysfunction after acute myocardial infarction than resting single photon emission computed tomographic thallium-201 scintigraphy. Am Heart J 1997;133:822-34. 
25. Spinelli L, Petretta M, Cuocolo A et al. Prediction of recovery of left ventricular dysfunction after acute myocardial infarction: comparison between $99 \mathrm{mTc}$-sestamibi cardiac tomography and low-dose dobutamine echocardiography. J Nucl Med 1999;40:1683-92.

26. Anselmi M, Golia G, Maines $M$ et al. Comparison between low-dose dobutamine echocardiography and thallium-201 scintigraphy in the detection of myocardial viability in patients with recent myocardial infarction. Int $J$ Cardiol 2000;73:213-23.

27. Wijns W, Vatner SF, Camici PG. Hibernating myocardium. N Engl J Med 1998;339:173-81.

28. Beller GA. Noninvasive assessment of myocardial viability. N Engl J Med 2000;343:1488-90.

29. Bax JJ, Poldermans D, Elhendy A et al. Sensitivity, specificity, and predictive accuracies of various non-invasive techniques for detecting hibernating myocardium. Curr Probl Cardiol 2001;26:141-86.

30. Underwood SR, Godman B, Salyani S et al. Economics of myocardial perfusion imaging in Europe-the EMPIRE Study. Eur Heart J 1999;20:157-66.

31. Nesto RW, Kowalchuk GJ. The ischemic cascade: temporal sequence of hemodynamic, electrocardiographic and symptomatic expressions of ischemia. Am J Cardiol 1987; 57:23C-30C.

32. Fung AY, Gallagher KP, Buda AJ. The physiologic basis of dobutamine as compared with dipyridamole stress interventions in the assessment of critical coronary artery stenosis. Circulation 1997;76:943-51.

33. Geleijnse ML, Marwick TH, Boersma E et al. Optimal pharmacological stress testing for the diagnosis of coronary artery disease: a probabilistic approach. Eur Heart J 1995; 16(Suppl M):3-10.

34. Houghton JL, Frank MJ, Car AA et al. Relations among impaired coronary flow reserve, left ventricular hypertrophy and thallium perfusion defects in hypertensive patients without obstructive coronary artery disease. J Am Coll Cardiol 1990;15:43-51.

35. DePeuy EG, Guertler-Krawczynska E, Perkins JV et al. Alterations in myocardial thallium-201 distribution in patients with chronic systemic hypertension undergoing 201 single-photon emission computed tomography. Am J Cardiol 1988;62:234-8.

36. Elhendy A, Geleijnse ML, van Domburg RT et al. Comparison of dobutamine stress echocardiography and technetium99m sestamibi single-photon emission tomography for the diagnosis of coronary artery disease in hypertensive patients with and without left ventricular hypertrophy. Eur J Nucl Med 1998;25:69-78.

37. Fragasso G, Lu C, Dabrowski P et al. Comparison of stress/ rest myocardial perfusion tomography, dipyridamole and dobutamine stress echocardiography for the detection of coronary disease in hypertensive patients with chest pain and positive exercise test. J Am Coll Cardiol 1999;34:441-7.

38. Wenger NK, Speroff L, Packard B. Cardiovascular health and disease in women. N Engl J Med 1993;329:247-56.

39. Mosca L, Manson JE, Sutherland SE et al. Cardiovascular disease in women. A statement for healthcare professionals from the American Heart Association. Circulation 1997; 96:2468-82.

40. Hansen CL, Crabbe D, Rubin S. Lower diagnostic accuracy of thallium-201 SPECT myocardial perfusion imaging in women: an effect of smaller chamber size. J Am Coll Cardiol 1996;28:1214-9.

41. Takeuchi M, Sonoda S, Miura Y et al. Comparative diagnostic value of dobutamine stress echocardiography and stress thallium-201 single-photon emission computed tomography for detecting coronary artery disease in women. Coron Artery Dis 1996;7:831-5.

42. Elhendy A, van Domburg RT, Bax JJ et al. Noninvasive diagnosis of coronary artery stenosis in women with limited exercise capacity: comparison of dobutamine stress echocardiography and $99 \mathrm{mTc}$ sestamibi single-photon emission CT. Chest 1998;114:1097-104.

43. Ho YL, Wu CC, Huang PJ et al. Assessment of coronary artery disease in women by dobutamine stress echocardiography: comparison with stress thallium-201 single-photon emission computed tomography and exercise electrocardiography. Am Heart J 1998;135:655-62.

44. Bisi G, Sciagra R, Santoro GM et al. Rest technetium-99m sestamibi tomography in combination with short-term administration of nitrates: feasibility and reliability for prediction of postrevascularisation outcome of asynergic territories. J Am Coll Cardiol 1994;24:1282-9.

45. Bax JJ, Patton JA, Poldermans D et al. 18Fluorodeoxyglucose imaging with PET and SPECT: cardiac applications. Semin Nucl Med 2000;30:281-8.

46. Braunwald E, Rutherford JD. Reversible ischemic left ventricular dysfunction: evidence for the hibernating myocardium. J Am Coll Cardiol 1986;8:1467-70.

47. Rahimtoola SH. The hibernating myocardium. Am Heart $J$ 1989;117:211-21.

48. Panza JA, Dilsizian V, Laurienzo JM et al. Relation between thallium uptake and contractile response to dobutamine. Implications regarding myocardial viability in patients with chronic coronary artery disease and left ventricular dysfunction. Circulation 1995;91:990-8.

49. Cornel JH, Bax JJ, Elhendy A et al. Agreement and disagreement between 'metabolic viability' and 'contractile reserve' in akinetic myocardium. J Nucl Cardiol 1999; 6:383-8.

50. Gerber BL, Vanoverschelde J-LJ, Bol A et al. Myocardial blood flow, glucose uptake and recruitment of inotropic reserve in chronic left ventricular ischemic dysfunction. Implications for the pathophysiology of chronic hibernation. Circulation 1996;94:651-9.

51. Baer FM, Voth E, Deutsch HJ et al. Predictive value of low dose dobutamine transesophageal echocardiography and fluorine-18 fluorodeoxyglucose positron emission tomography for recovery of regional left ventricular function after successful revascularization. J Am Coll Cardiol 1996; 28:60-9.

52. Pagano D, Bonser RS, Townend JN et al. Predictive value of dobutamine echocardiography and positron emission tomography in identifying hibernating myocardium in patients with postischaemic heart failure. Heart 1998;79:281-8.

53. Vanoverschelde J-LJ, D'Hondt A-M, Marwick T et al. Headto-head comparison of exercise-redistribution-reinjection thallium single-photon emission computed tomography and low dose dobutamine echocardiography for prediction of reversibility of chronic left ventricular ischemic dysfunction. J Am Coll Cardiol 1996;28:432-42.

54. Arnese M, Cornel JH, Salustri A et al. Prediction of improvement of regional left ventricular function after surgical revascularization: a comparison of low-dose dobutamine echocardiography with 201-TL SPECT. Circulation 1995; 91:2748-52.

55. Bax JJ, Cornel JH, Visser FC et al. Prediction of recovery of myocardial dysfunction following revascularization; Comparison of F18-fluorodeoxyglucose/thallium-201 single photon emission computed tomography, thallium-201 stress-reinjection single photon emission computed 
tomography and dobutamine echocardiography. J Am Coll Cardiol 1996;28:558-64.

56. Haque $T$, Furukawa $T$, Takahashi $M$ et al. Identification of hibernating myocardium by dobutamine stress echocardiography: Comparison with thallium-201 reinjection imaging. Am Heart J 1995;130:553-63.

57. Kostopoulos KG, Kranidis AI, Bouki KP et al. Detection of myocardial viability in the prediction of improvement of left ventricular function after successful coronary revascularization by using dobutamine stress echocardiography and quantitative SPECT rest-redistribution-reinjection 201Tl imaging after dipyridamole infusion. Angiology 1996; 47:1039-46.

58. Marzullo $P$, Parodi $O$, Reisenhofer $B$ et al. Value of rest thallium-201/technetium-99m Sestamibi and dobutamine echocardiography for detecting myocardial viability. Am J Cardiol 1993;71:166-72.

59. Qureshi U, Nagueh SF, Afridi I et al. Dobutamine echocardiography and quantitative rest-redistribution 201Tl tomography in myocardial hibernation. Relation of contractile reserve to 201Tl uptake and comparative prediction of recovery of function. Circulation 1997;95:626-35.

60. Alfieri O, La Canna G, Giubinni R et al. Recovery of myocardial function. Eur J Cardiothorac Surg 1993;7:325-30.

61. Perrone-Filardi $P$, Pace $L$, Prastaro $M$ et al. Assessment of myocardial viability in patients with chronic coronary artery disease. Rest-4-hour-24-hour 201Tl tomography versus dobutamine echocardiography. Circulation 1996;94: 2712-9.

62. Charney R, Schwinger ME, Chun J et al. Dobutamine echocardiography and resting-redistribution thallium-201 scintigraphy predicts recovery of hibernating myocardium after coronary revascularization. Am Heart J 1994; 128:864-9.

63. Nagueh SF, Vaduganathan $\mathrm{P}$, Ali $\mathrm{N}$ et al. Identification of hibernating myocardium: comparative accuracy of myocardial contrast echocardiography, rest-redistribution thallium-201 tomography and dobutamine echocardiography. J Am Coll Cardiol 1997;29:985-93.

64. Pace L, Perrone-Filardi P, Mainenti P et al. Combined evaluation of rest-redistribution thallium-201 tomography and low-dose dobutamine echocardiography enhances the identification of viable myocardium in patients with chronic coronary artery disease. Eur J Nucl Med 1998;25:744-50.

65. Senior R, Glenville B, Basu S et al. Dobutamine echocardiography and thallium-201 imaging predict functional improvement after revascularization in severe ischaemic left ventricular dysfunction. Br Heart J 1995;74:358-64.

66. Sicari R, Varga A, Picano E et al. Comparison of combination of dipyridamole and dobutamine during echocardiography with thallium scintigraphy to improve viability detection. Am J Cardiol 1999;83:6-10.

67. Gunning MG, Anagnostopoulos C, Knight CJ et al. Comparison of 201Tl, $99 \mathrm{mTC}$-tetrofosmin, and dobutamine magnetic resonance imaging for identifying hibernating myocardium. Circulation 1998;98:1869-74.

68. Corbett JR, Ficaro EP. Attenuation corrected cardiac perfusion SPECT. Curr Opin Cardiol 2000;15:330-6.

69. Germano G. Technical aspects of myocardial SPECT imaging. J Nucl Med 2001;42:1499-507.

70. Caidahl K, Kazzam E, Lidberg J et al. New concept in echocardiography: harmonic imaging of tissue without use of contrast agent. Lancet 1998;352:1264-70.

71. Sozzi FB, Poldermans D, Bax JJ et al. Second harmonic imaging improves sensitivity of dobutamine stress echo- cardiography for the diagnosis of coronary artery disease. Am Heart J 2001;142:153-9.

72. Hundley WG, Kizilbash AM, Afridi I et al. Administration of an intravenous perfluorocarbon contrast agent improves echocardiographic determination of left ventricular volumes and ejection fraction: comparison with cine magnetic resonance imaging. J Am Coll Cardiol 1998;32:1426-32.

73. Mor-Avi V, Lang RM. Recent advances in echocardiographic evaluation of left ventricular anatomy, perfusion, and function. Cardiol Rev 2001;9:146-59.

74. Waggoner AD, Bierig SM. Tissue Doppler imaging: a useful echocardiographic method for the cardiac sonographer to assess systolic and diastolic ventricular function. J Am Soc Echocardiogr 2001;14:1143-52.

75. Kaul S. Myocardial contrast echocardiography: basic principles. Prog Cardiovasc Dis 2001;44:1-11.

76. Germano G, Berman DS. Quantitative gated SPECT. J NuCl Med 2001;42:528-9.

77. Germano G. Automatic analysis of ventricular function by nuclear imaging. Curr Opin Cardiol 1998;13:425-9.

78. Smanio PE, Watson DD, Segalla DL et al. Value of gating of technetium-99m sestamibi single-photon emission computed tomographic imaging. J Am Coll Cardiol 1997; 30:1687-92.

79. Sharir T, Germano G, Kavanagh PB et al. Incremental prognostic value of post-stress left ventricular ejection fraction and volume by gated myocardial perfusion single photon emission computed tomography. Circulation 1999; 100:1035-42.

80. Kaul S, Senior R, Dittrich $\mathrm{H}$ et al. Detection of coronary artery disease with myocardial contrast echocardiography: comparison with $99 \mathrm{mTc}$-sestamibi single-photon emission computed tomography. Circulation 1997;96:785-92.

81. Marwick TH, Brunken R, Meland $\mathrm{N}$ et al. Accuracy and feasibility of contrast echocardiography for detection of perfusion defects in routine practice: comparison with wall motion and technetium-99m sestamibi single-photon emission computed tomography. The Nycomed NC100100 investigators. J Am Coll Cardiol 1998;32:1260-9.

82. Jucquois I, Nihoyannopoulos $P$, D'Hondt $A M$ et al. Comparison of myocardial contrast echocardiography with NC100100 and $(99 \mathrm{~m})$ Tc sestambi SPECT for detection of resting myocardial perfusion abnormalities in patients with previous myocardial infarction. Heart 2000;83:518-24.

83. Wei K, Jayaweera AR, Firoozan S et al. Quantification of myocardial blood flow with ultrasound-induced destruction of microbubbles administered as a constant venous infusion. Circulation 1998;97:473-83.

84. Wei K. Detection and quantification of coronary stenosis severity with myocardial contrast echocardiography. Prog Cardiovasc Dis 2001;44:81-100.

85. Lepper W, Hoffmann R, Kamp O et al. Assessment of myocardial reperfusion by intravenous myocardial contrast echocardiography and coronary flow reserve after primary percutaneous transluminal coronary angioplasty [correction of angiography] in patients with acute myocardial infarction. Circulation 2000;101:2368-74.

86. Ito $\mathrm{H}$, Tomooka $\mathrm{T}$, Sakai $\mathrm{N}$ et al. Lack of myocardial perfusion immediately after successful thrombolysis. A predictor of poor recovery of left ventricular function in anterior myocardial infarction. Circulation 1992;85:1699-785.

87. Main ML, Magalski A, Chee NK et al. Full-motion pulse inversion power Doppler contrast echocardiography differentiates stunning from necrosis and predicts recovery of left ventricular function after acute myocardial infarction. $\mathrm{J} \mathrm{Am}$ Coll Cardiol 2001;38:1390-4. 
88. Nagueh SF, Vaduganathan $\mathrm{P}$, Ali $\mathrm{N}$ et al. Identification of hibernating myocardium: comparative accuracy of myocardial contrast echocardiography, rest-redistribution thallium-201 tomography and dobutamine echocardiography. J Am Coll Cardiol 1997;29:985-93.
89. Bax JJ, Visser FC, Poldermans D et al. Time course of functional recovery of stunned and hibernating segments after surgical revascularization. Circulation 2001; 104:1314-8. 